\title{
Geopolymers and other alkali activated materials - Why, how, and what?
}

\author{
John L. Provis \\ Department of Materials Science and Engineering, University of Sheffield, Sir Robert \\ Hadfield Building, Mappin St, Sheffield S1 3JD, United Kingdom
}

Email: j.provis@sheffield.ac.uk, phone +44 114222 5490, fax +44 1142225943

\begin{abstract}
This paper presents a review of alkali-activation technology, moving from the atomic scale and chemical reaction path modelling, towards macroscopic observables such as strength and durability of alkali-activated concretes. These properties and length scales are intrinsically interlinked, and so the chemistry of both low-calcium ('geopolymer') and highcalcium (blast furnace slag-derived) alkali-activated binders can be used as a starting point from which certain engineering properties may be discussed and explained. These types of materials differ in chemistry, binder properties, chemical structure and microstructure, and this leads to the specific material properties of each type of binder. The secondary binder products formed during alkali-activation (zeolites in low-Ca systems, mostly layered double hydroxides in alkali-activated slags) are of significant importance in determining the final properties of the materials, particularly in the context of durability. The production of highly durable concretes must remain the fundamental aim of research and development in the area of alkali-activation. However, to enable the term 'highly durable' to be defined in a satisfactory way, the underlying mechanisms of degradation - which are not always the same for alkali-activated binders as for Portland cement-based binders, and cannot always be tested in precisely the same ways - need to be further analysed and understood. The process of reviewing a topic such as this will inevitably raise just as many questions as answers, and it is the intention of this paper to present both, in appropriate context.
\end{abstract}

Keywords: Alkali-activation; geopolymer; chemical reaction modelling; binder chemistry; durability. 


\section{Introduction - why are alkali-activated materials attracting such interest?}

This paper is structured as a review spanning areas of science and engineering related to the uptake of alkali-activated binders as construction materials. This is an area in which scientific and technological developments are currently being made at a rapid pace, and so it is both timely and necessary to consider the context surrounding these developments, and also the scientific underpinnings of alkali-activation technology. A much more detailed overview of many of the engineering aspects of alkali-activation, in particular durability testing, is presented in the State-of-the-Art report of RILEM TC 224-AAM [1]. So, this paper will be focused on understanding fundamental chemical mechanisms and the application of advanced characterisation tools to alkali-activated materials, particularly highlighting the application of advanced spectroscopic methods and chemical reaction engineering techniques in the development of novel construction materials.

Alkali-activated binders, including the materials referred to as 'geopolymers', have attracted much interest in academic and commercial spheres over the past decade or more. These materials are produced through the reaction of an aluminosilicate - normally supplied in powder form as an industrial by-product or other inexpensive material [2] - with an alkaline activator, which is usually a concentrated aqueous solution of alkali hydroxide, silicate, carbonate or sulfate $[1,3]$. The name 'geopolymer' was introduced by Davidovits in the 1970 s [4], but the technology of alkali-activation predates this terminology by more than 60 years, with a patent awarded to Kühl in 1908 [5], research and commercial work conducted in Belgium by Purdon from the 1930s-1950s [6, 7], and an extensive program of research, development and commercial-scale production growing from the work of Glukhovsky in Kiev from the 1950 onwards [8, 9]. More recent commercial development work has led to the larger scale availability, and regulatory standardisation, of alkali-activated concretes in various parts of the world [1, 10-12].

The key reason why alkali-activation is gaining increasing recognition and interest, after more than 100 years of sporadic utilisation, is related to the potential for $\mathrm{CO}_{2}$ emission reductions when alkali-activated materials are used in place of Portland cement-based materials. Because the majority of the material in an alkali-activated binder is generally derived from industrial by-products, to which little or no environmental footprint is usually attributed [13], these binders have been identified as offering the potential for notable Greenhouse emissions savings when compared with Portland cement [12, 14]. It is not the purpose of this review to address this issue in detail, beyond making the comment that it is evident that there is an urgent need for updated life-cycle inventory databases to enable fully 
accurate description of the various aspects of the emissions footprint of an alkali-activated binder, particularly with regard to the contribution of alkali silicates used as activators in these materials [15].

The availability of such information will bring more consistency to the currently very diverse outcomes of published life-cycle analysis studies of alkali-activated binder systems. The current state of the art in this area is that a strong dependence of emissions profiles on mix design and geographic parameters has been made evident [16], and the importance of some non- $\mathrm{CO}_{2}$ emissions categories highlighted [17]. It is undoubtedly possible to produce alkaliactivated binders with a $\mathrm{CO}_{2}$ emission profile which provides savings compared to Portland cement-based concretes, if the supply chain and mix design are developed with sustainability outcomes in mind. However, neglecting these issues throughout the materials design process can also lead to a situation in which an alkali-activated material shows an emissions profile worse than that of Portland cement-based concretes. The widely-advertised high levels of $\mathrm{CO}_{2}$ emissions savings are not necessarily intrinsic to the whole class of materials, but rather can be achieved through careful and appropriate design of fit-for-purpose materials for the correct applications.

Alkali-activated binders have also been widely advertised as showing potential for commercially attractive properties are in applications requiring chemical (acid) resistance or high-temperature resistance [4, 18]. These properties are generally achieved through the presence of an alkali aluminosilicate gel, as opposed to a calcium silicate hydrate type gel; the highly crosslinked (Q4) nature of the aluminosilicate 'geopolymer'-type gel [19], and the resulting low bound water content, provide these properties to low-calcium alkali-activated binders. Some higher-calcium alkali-activated binders can also show good chemical durability [20, 21], while the high-temperature properties of alkali-activated slag have been shown to be improved through blending with metakaolin as a secondary $\mathrm{Al}$ source [22]. The high early strength of some alkali-activated binder mixes has been widely advertised as a potentially advantageous property, but this is mainly achievable in slag-rich binders or metakaolin-based alkali-activated materials, and is much less widely observed in fly ashbased systems cured under an ambient environment.

For this and other reasons, it is critical to recognise that alkali-activated binders - and even the subset of these materials which are known as geopolymers - are an extremely diverse grouping of materials. Their properties can thus fall almost anywhere in the range from 'high' to 'low' according to almost any criterion by which the performance of a material can be measured, and so it is impossible to provide a list of properties which are in any way 'characteristic' of alkali-activated materials in general. Because of this diversity, it is essential 
to develop a detailed molecular-level understanding of the chemical and physical characteristics which control the macroscopically measurable performance of alkaliactivated materials, to enable the engineered design of materials which provide desirable properties in a predictable and reliable way.

\section{Binders for the future: Diversification for performance and sustainability}

In many academic studies, novel cements are presented - in common with many other types of new materials discussed in the broader materials science literature - as 'a solution in search of a problem'. The attitude of many researchers has been that if a new material is are able to be discussed from a scientific perspective, the attractiveness of technical properties will necessarily lead to some form of commercial uptake for a particular application. In the context of waste utilisation (or beneficiation, or valorisation), this often takes the form of a publication in an academic journal, which shows that an existing widely-used material can be blended with a given percentage of waste derived from a specific process/source, without compromising its performance to an unacceptable degree. However, considering the relatively limited volume of waste materials generated from any single process when compared with the usual throughput of a commercial-scale cement or concrete production facility, and the high variability from month to month (or even from day to day) in many such waste streams, it is essential for researchers to provide information on a more fundamental chemical/mineralogical level, to enable published results to be more broadly useful beyond the very limited number of workers who happen to have access to exactly the same supply of raw (or waste) materials. It is this more generic information which is of value in moving any new binder technology from being 'a solution in search of a problem' to ' $a$ solution to an actual problem'.

The global construction materials community is currently facing increasing commercial and technological pressures from multiple competing factors, including:

- The need to reduce emissions of $\mathrm{CO}_{2}$ and other environmental pollutants on both national and international levels, under different regulatory regimes worldwide

- Increasing demand for cement and concrete in developing and middle-income nations, in parallel with reducing or stagnant demand in developed/OECD nations

- Increasing material performance requirements resulting from more ambitious architectural, structural and/or engineering design

- Increased durability (service life) requirements, including the consideration that, on a full life-cycle basis, sustainability and durability must be viewed in parallel 
- The desire (and requirement) to recycle industrial wastes and by-products, rather than landfilling these potentially valuable materials

- The need to avoid generation of human or environmental health hazards through release of contaminants from consumer products containing recycled industrial wastes or by-products

These factors are all providing strong incentives for innovation in the development and use of construction materials. However, the fact that the production of construction materials is inherently a high volume/low margin industry requiring large capital investment to develop any new production facility, operating within a regulatory framework which is necessarily conservative, is a significant hindrance to the uptake of novel technologies. Nonetheless, advances such as organic superplasticisers, blended Portland cement binders and ultra-highperformance concretes are meeting with broad market acceptance. There are now standards regimes in force in various parts of the world which allow the use of binders not based on Portland cement chemistry - including explicit description of non-Portland binders in standards in force in some parts of the EU, several former Soviet nations, China, and some states of Australia, as well as via the performance-based standards which are gaining in acceptance in the USA. These regulatory developments are discussed in more detail in the State-of-the-Art Report of RILEM TC 224-AAM [1], and research and innovation are leading to a fundamental philosophical shift towards performance-based standards regimes in the global construction industry [23], and this is driving larger-scale development of technologies such as alkali-activation. In this context, some discussion of key results from the past decade of research in this field will be presented in the following sections.

\section{Reaction mechanisms and processes in alkali activation}

In any discussion of a material formed through a chemical reaction process, a logical place to commence the structural and chemical analysis of the material is through understanding the mechanism by which it is formed. In the case of alkaline activation, this is a solutionmediated process, and so the reactions taking place between the alkaline activating solution and the solid aluminosilicate precursors define the nature of the product formed. This extends beyond simple chemical effects, as the importance (beneficial or detrimental) of any chemical reaction is defined fundamentally not only by what the reaction is, but also when it takes place, and where within the structure of the reaction mixture. This means that chemical reaction engineering is fundamental in underpinning the science and technology of alkali-activation. This section will address issues in this area, particularly focusing on the 
role of particle-fluid reaction processes in enabling the development of alkali-activated binders with more attractive performance in either the fresh or hardened state.

\subsection{Conceptual and mathematical models for alkaline activation processes}

The reaction mechanism involved in the alkaline activation of an aluminosilicate source is often described, following the initial concepts developed by Glukhovsky in the 1950s-1970s, and since expanded and refined by many others [24], as a process of dissolution, rearrangement, condensation and re-solidification. The first detailed mechanistic model of this system was developed by Provis and Van Deventer [25], parameterised and validated by comparison with data obtained through energy-dispersive X-ray diffractometry (EDXRD) [26] and alternating current impedance spectroscopy (ACIS) [27]. The model framework itself was based on an earlier description of the weathering of aluminosilicate minerals [28], extended to incorporate the formation of multiple aluminosilicate products with different degrees of cross-linking, as well as inclusion of the oligomerisation which takes place among silicate species in concentrated solution [29, 30]. Figure 1 presents a schematic depiction of this mathematical model. 


\section{Structure}

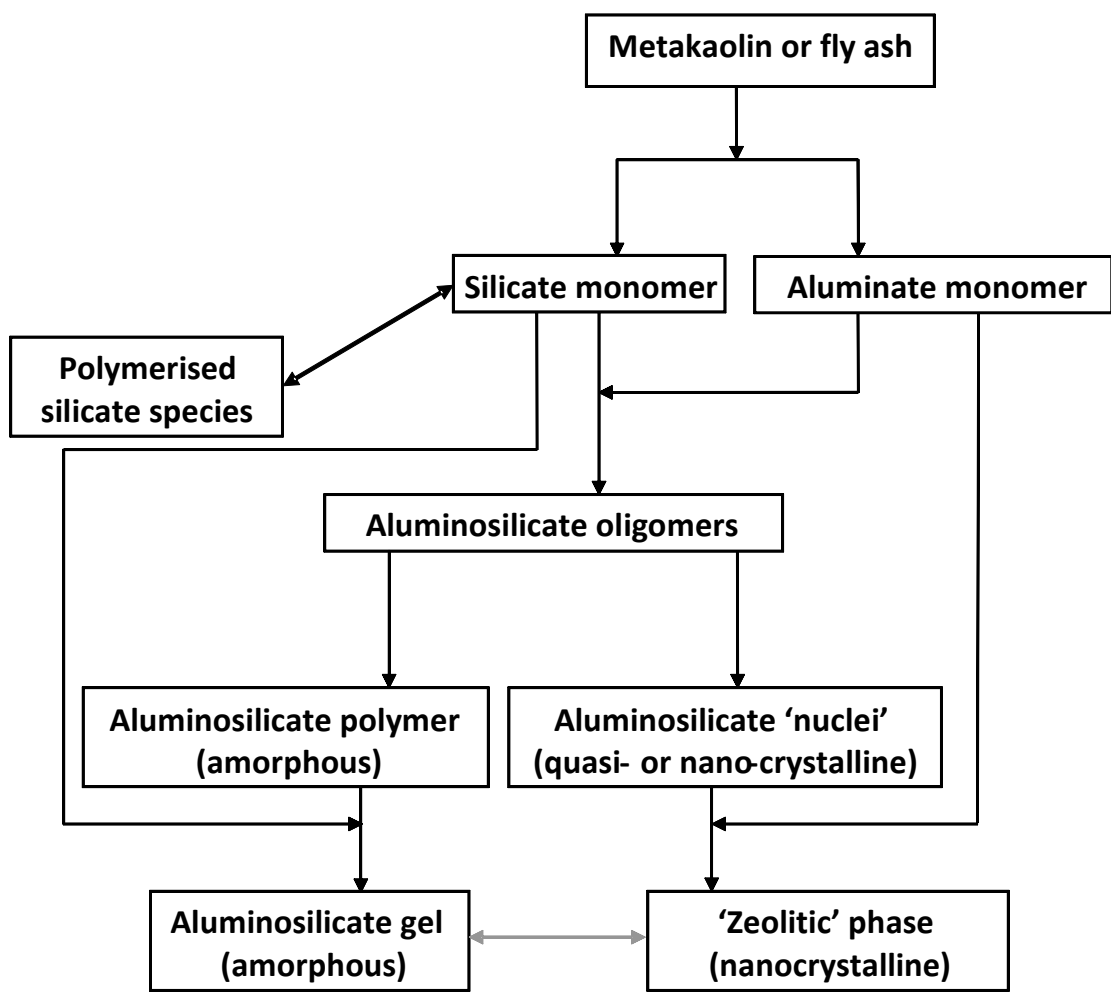

Layered or glassy aluminosilicate

Dissolved $\left(Q^{\circ}\right)$

Dissolved $\left(Q^{1} / Q^{2}\right)$

Dissolved $\left(Q^{1} / Q^{2}\right)$

Initial gel formation $\left(Q^{3}\right)$

Final gel formation $\left(Q^{4}\right)$

Figure 1. Schematic diagram of a conceptual/mathematical model for alkaline activation of a low-Ca aluminosilicate source such as metakaolin or low-Ca (siliceous/Class F) fly ash. Developed from concepts presented in [25] and extended in [27].

The application of this model to the description of the reaction processes taking place during the reaction of metakaolin to form a geopolymer gel has proven successful, particularly in comparison with ACIS data [27], which were able to provide a quantitative time scaling to the model, Figure 2. 


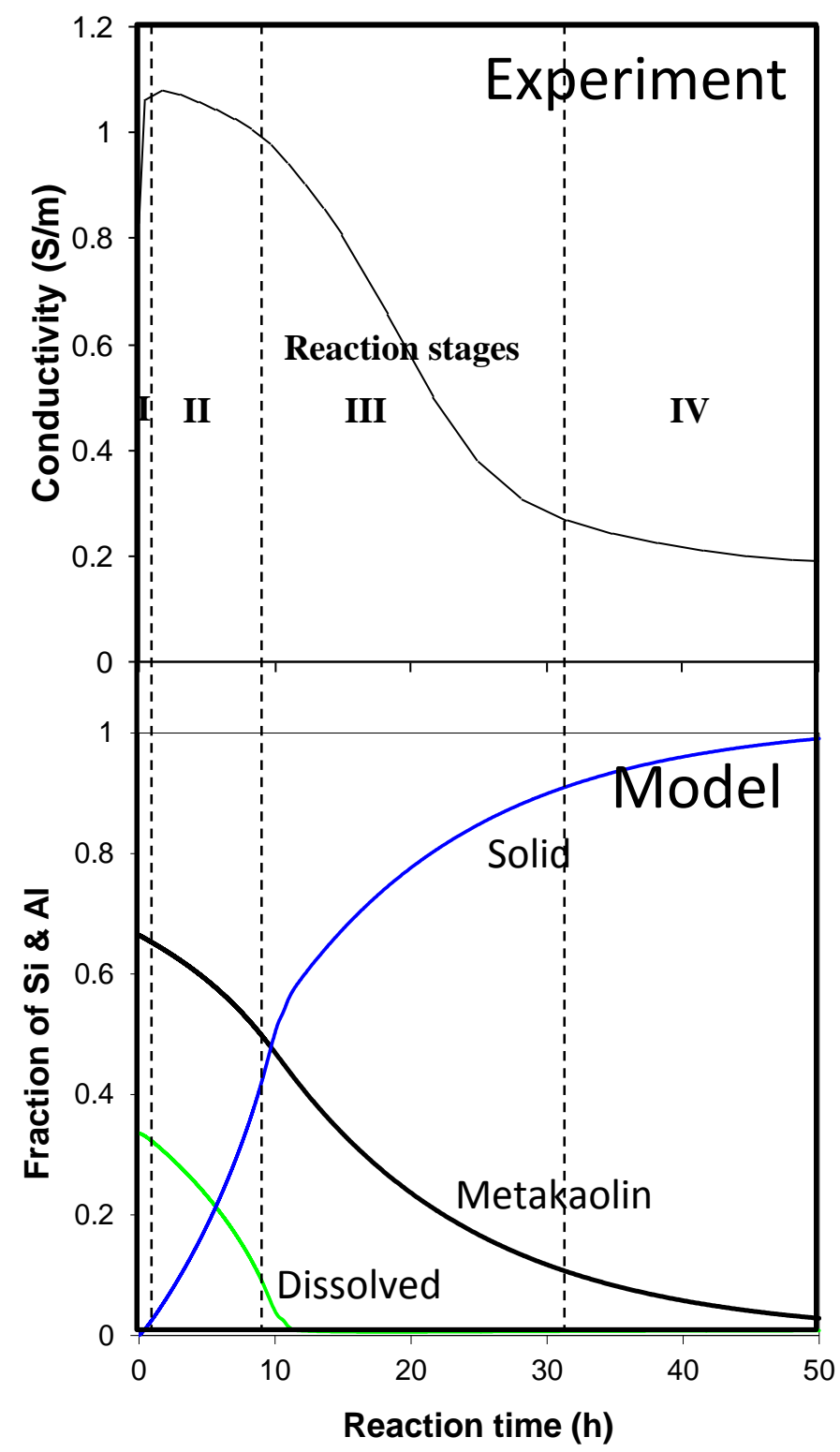

Figure 2. Correspondence between model predictions of structural evolution during the reaction of metakaolin with a sodium silicate solution $\left(\mathrm{SiO}_{2} / \mathrm{Na}_{2} \mathrm{O}\right.$ molar ratio 2.0), using the model outlined in Figure 1 , and the evolution of conductivity with reaction time as measured by ACIS. Reaction stages are identified as: I, dissolution; II, dissolution and reorientation; III, gelation; and IV, cross-linking. Data from [27].

This approach to modelling provides detailed insight into the influence of various chemical parameters (water content, $\mathrm{Si} / \mathrm{Al}$ ratio, temperature), and some simple physical parameters (particle surface area), on the reaction processes taking place during the reaction between a solid aluminosilicate and an alkaline solution. However, it is limited by its lack of scalability to include additional reaction pathways or components - meaning that, for example, it has not yet proven possible to describe alkaline-activation reactions involving calcium using this methodology, because the fundamental reaction steps are defined in terms of the formation of Si-O-(Si,Al) bonds, and the greater crystal-chemical complexity of the Ca-containing 
reaction products (partially ordered silicate chain structures as well as discrete Ca-rich hydrate phases) is not so readily described by an essentially polymerisation-based modelling framework. The products of alkaline activation of slag have been described by thermodynamic [31], stoichiometric [32] and gel nanostructural [33, 34] models, but no detailed reaction-path description of this process has yet been published.

The other main shortcoming of a purely reaction kinetics-based approach to the description of alkali activation is that the influence of spatially-resolved processes (particularly those which take place at particle-fluid interfaces) is not captured accurately by equations formulated on a bulk concentration basis. This is even the case when the rates are scaled by particle surface area, because the effects of mass transport through the fluid to the interface, where the reaction takes place, are still not able to be captured accurately. The fact that alkaline activation is controlled to such a large extent by molecular-scale processes led to this length scale as being the preferred starting point for the development of a spatially-resolved mathematical description of the process, and this simulation methodology appears to be more readily scaleable than the reaction path modelling described in the preceding paragraphs.

In describing the three-dimensional nanostructural development of an alkali-activated binder on a molecular length scale, it is obviously necessary to make some compromises regarding the level of granularity of the model, to enable a relatively representative volume of material to be described within a computationally accessible timeframe. For metakaolin geopolymerisation, the obvious units to use in such a coarse-graining procedure are monomeric silicate or aluminate species, and so the most fundamental model parameters then become the interaction energies between these units, describing the likelihood of Si-O( $\mathrm{Si}, \mathrm{Al})$ bond formation. These energies can be calculated directly via density functional theory [35], which provides information on the energetics of the bond formation/breakage processes when two $\mathrm{Si}$ or $\mathrm{Al}$ units are in close proximity with each other. The use of these interaction energies in a coarse-grained Monte Carlo modelling framework, where bonds can break and form between monomers (which are the fundamental units used in the coarsegraining procedure, Figure 3), and monomeric units can move in space according to diffusion-like processes, provides an opportunity to generate three-dimensional information regarding the fundamental nature of the silicate [36] and aluminosilicate [37] gels which form during the geopolymerisation of metakaolin, and in other related systems such as hydrothermal zeolite synthesis. 

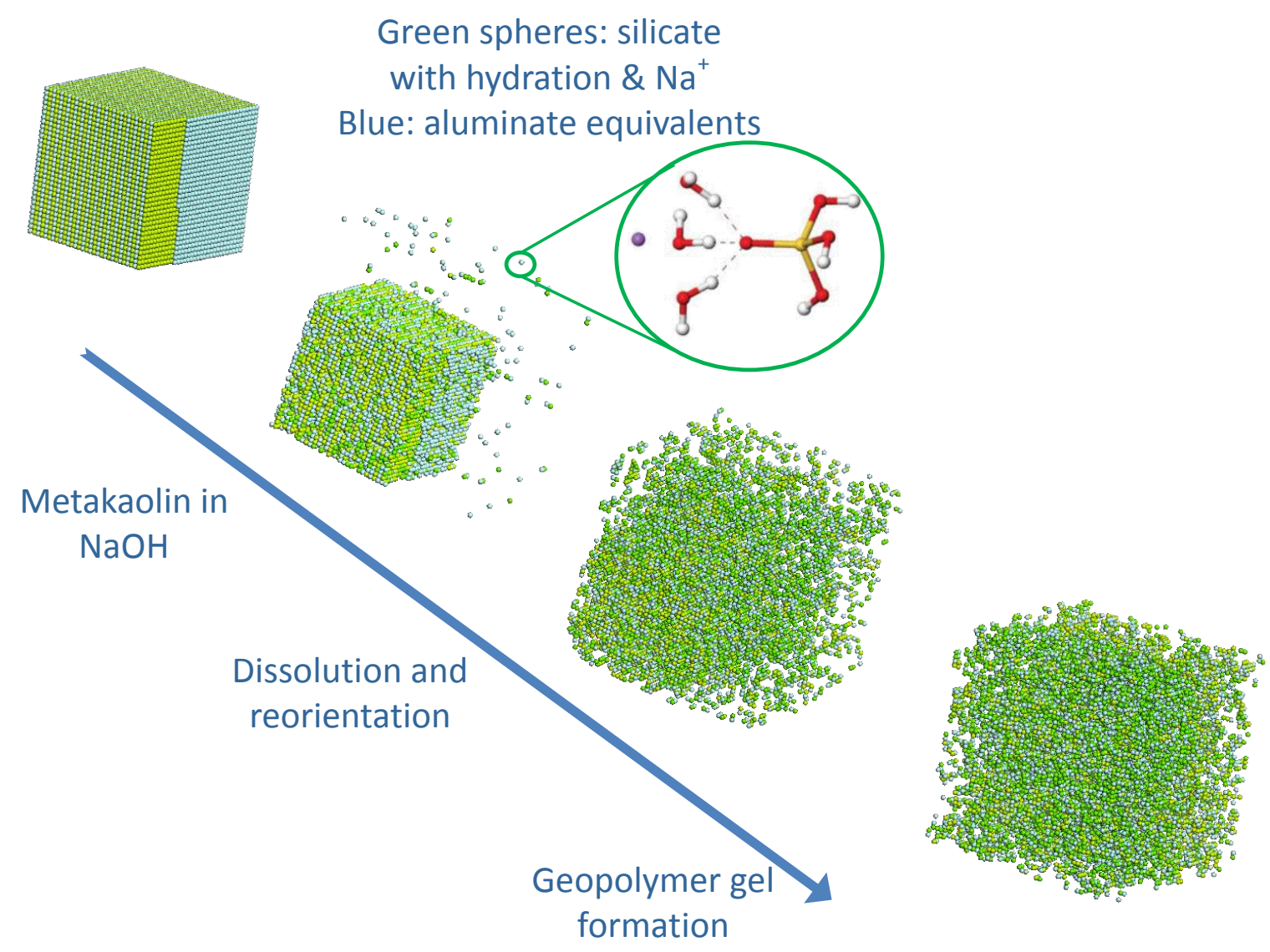

Figure 3. Schematic of the description of metakaolin geopolymerisation by a coarse-grained Monte Carlo model [37], demonstrated as the reaction of a solid layered aluminosilicate particle (top left) into a solution region filled with $\mathrm{NaOH}$, with reorientation and geopolymer gel formation processes taking place over time.

Figure 3 shows that this approach to mathematical simulation of the geopolymerisation process is able to reproduce the fundamental microstructural characteristics of the reaction process: the layered metakaolin particle is attacked by the alkaline solution, and the aluminate and silicate units released by its dissolution can then rearrange and grow into a gel which becomes space-filling. Differences in the nature of the gel, and the mechanism of its reaction, can be identified when changing from a hydroxide activating solution to a silicaterich solution, with processes such as Ostwald ripening identifiable through analysis of the evolution of cluster size distributions as a function of time [37]. The direct mapping of the Monte Carlo reaction steps onto a real-world time scale has not yet proven possible, but work related to the extension of this model is ongoing, and the scaleability of the fundamental model architecture means that this approach provides scope for much broader application and extension in future. 
Having discussed the theoretical description of alkali-activation reaction processes, it is essential to also comment on the techniques available for the characterisation of such processes, using laboratory or beamline instruments. The focus here is on less-widely-used techniques, rather than more standard laboratory methods such as isothermal calorimetry; while such methods are certainly able to provide useful information regarding alkaliactivation [38-44], they are generally well-understood, and can be applied in much the same way as for Portland cement-based systems, and have been reviewed in more detail in [45].

The rapid reaction of many geopolymer formulations means that a short measurement time per point is essential for in situ analysis; synchrotron radiation is particularly valuable in enabling collection of in situ scattering data during geopolymer formation [26, 46-48], while some specialised laboratory instruments can also provide in situ data [49], and in situ neutron scattering can also be conducted, albeit at a lower time resolution (timescale of minutes rather than seconds for a synchrotron source) [50]. Attenuated total reflectance (ATR) geometry provides the opportunity to conduct Fourier transform infrared (FTIR) spectroscopy in situ; it is possible to collect data in timesteps of less than a minute, as shown in Figure 4. Data such as these have been used in the study of geopolymerisation, to provide understanding of the role of alkali content [51], seeded nucleation $[52,53]$, and the release rates and availability of silica and alumina [54, 55]. The combination of time resolved ATRFTIR data with spatially-resolved infrared microscopy data [53-55] has proven to be particularly valuable in understanding the details of chemical heterogeneity within geopolymer gels. 


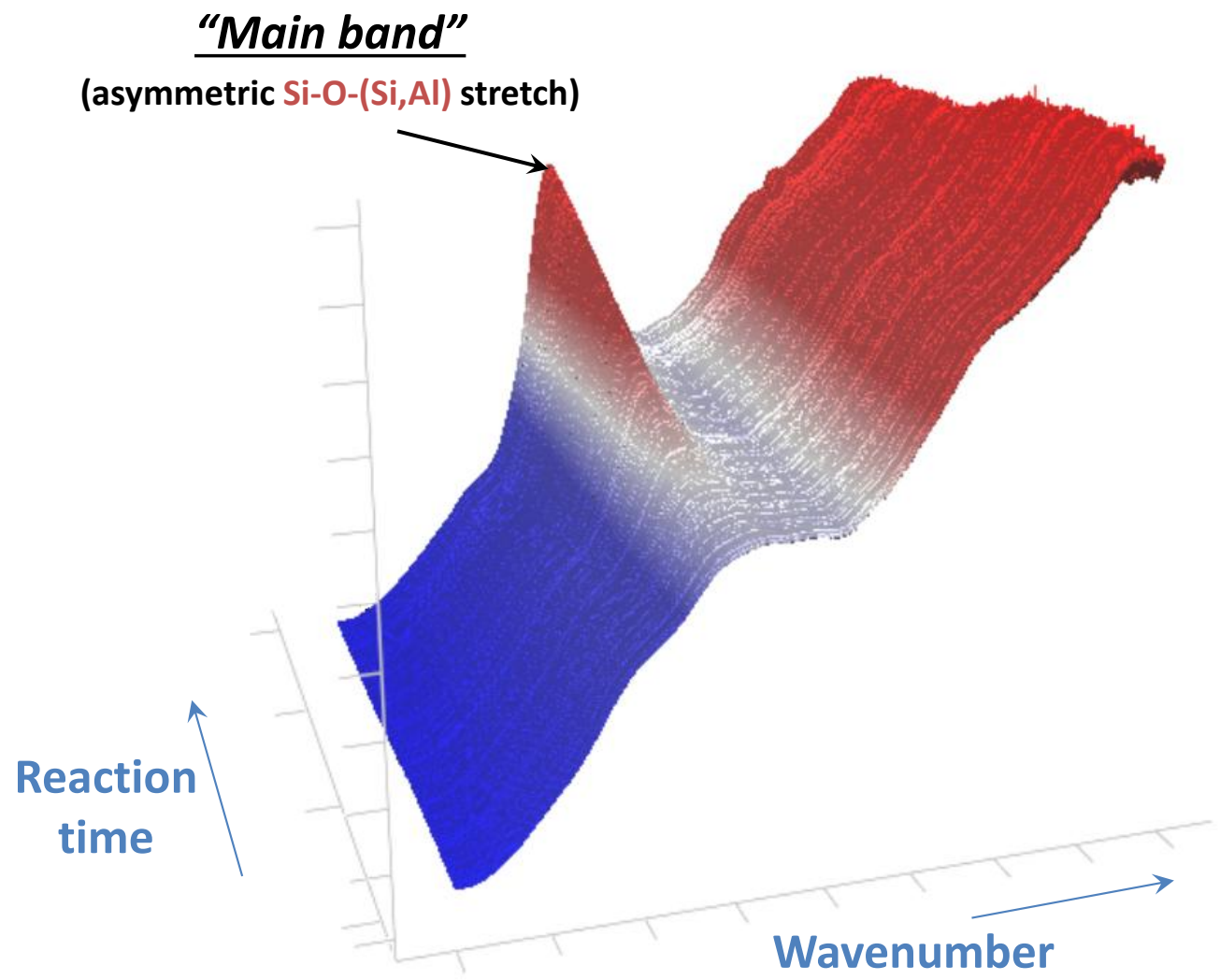

Figure 4. Example of the raw spectral data which can be obtained from in situ ATR-FTIR analysis of geopolymerisation. Data shown are one spectrum per minute for the first 50 hours of reaction, in the wavenumber range $500-1300 \mathrm{~cm}^{-1}$, for the reaction of fly ash with $\mathrm{NaOH}$ solution at $40^{\circ} \mathrm{C}$. Data from [51].

This understanding of reaction mechanisms is the first essential step in developing the ability to tailor binders for durability and performance [2], which is intrinsically interlinked with the next topic to be discussed in this review, the nature of the hardened binder itself.

\section{Chemistry and structure of hardened alkali-activated binders}

\subsection{Low-calcium alkali-activated binders ('geopolymers')}

The category of materials broadly described as 'alkali-activated materials' are extremely diverse in structure and chemistry, and so they will be discussed in two categories according to calcium content here, as this appears to be the main determinant in whether the binder is network-like or chain-like in terms of silicate structures.

Low-calcium aluminosilicate precursors such as fly ash and metakaolin are most commonly activated with alkali metal hydroxide or silicate solutions, and a relatively high $\mathrm{pH}$ is required to induce the reaction of these precursors. The gel structural units present in a 
calcium-free alkali aluminosilicate binder (corresponding to the reaction mechanism in Figure 1) can be viewed as the disordered analogue of an aluminosilicate zeolite-like structure [56], where the local ordering of $\mathrm{Si}$ and $\mathrm{Al}$ is determined by the thermodynamic energy penalty associated with $\mathrm{Al}-\mathrm{O}-\mathrm{Al}$ bond formation [57]. The thermodynamic preference for Al-O-Al bond avoidance is sufficiently strong that as long as the $\mathrm{Si} / \mathrm{Al}$ ratio is at least slightly higher than 1.o, the materials can be described as following the 'Loewenstein rule' [58], which states that Al-O-Al bonds are strongly disfavoured in tetrahedral structures. This explains why crystalline zeolites are the most common secondary phase identified in lowcalcium alkali-activated binder systems, with commonly observed zeolite species including faujasite-type structures (particularly zeolite Na-X), chabazite-Na, gismondine-group phases, hydrosodalite and/or hydroxysodalite, analcime-group structures (including the potassium and caesium analogues, leucite and pollucite), and zeolite Na-A.

On this basis, it is reasonable to expect that the local structure of the geopolymer gel would be in some sense similar to the local structure of these types of zeolites. This was proposed initially by Davidovits [59] on the basis of initial magic angle spinning nuclear magnetic resonance (MAS NMR) spectroscopy studies of metakaolin-derived binders, and the collection of higher-resolution ${ }^{29} \mathrm{Si}$ MAS NMR spectra for materials derived from both metakaolin [19, 60, 61] and fly ash [62, 63], has provided further support for this identification. However, NMR spectroscopy provides limited structural information beyond the nearest tetrahedral neighbour, due to the broad the peaks inherent in solid-state analysis of disordered materials, and the same is true for infrared spectroscopy, and many other atomic or molecular spectroscopy-based techniques. This length scale between the atomic level (a few Ångstroms) and the length scales probed through traditional crystallography (tens of nanometres) is accessible only through a limited number of analytical techniques which can be applied to complex materials; the one of these which has been of the most value to date in the analysis of low-calcium alkali-activated binders is pair distribution function (PDF) analysis [64-66]. This technique involves taking the Fourier transform of highresolution, high-momentum transfer ('high- $Q$ ', where $Q=\frac{4 \pi_{\sin } \theta}{\lambda}$ ) X-ray or neutron scattering data, which provides real-space information regarding interatomic correlations, as shown in Figure 6. Here, a horizontal line represents a structure which is essentially random with regard to atomic positions at that length scale, while peaks and troughs represent either an increased or decreased probability of finding atoms (or, more precisely, scattering density - which may be negative in the case of neutrons) separated by a distance $r$. 


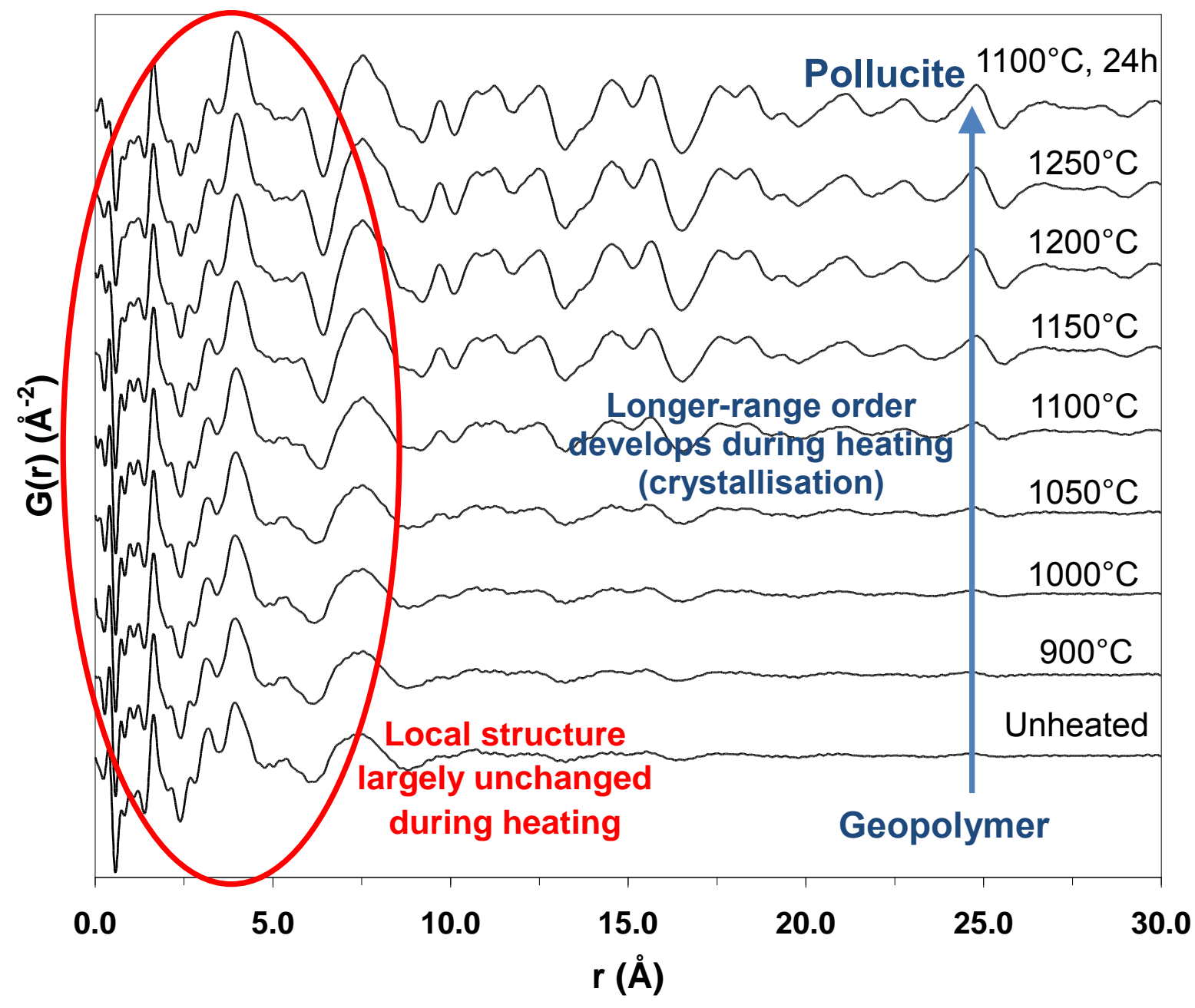

Figure 5. Example of X-ray pair distribution function data for a geopolymer of composition $\mathrm{Cs}_{2} \mathrm{O} \cdot \mathrm{Al}_{2} \mathrm{O}_{3} \cdot 4 \mathrm{SiO}_{2} \cdot n \mathrm{H}_{2} \mathrm{O}$, both as-synthesised (bottom), and heated to temperatures as marked at a heating rate of $10^{\circ} \mathrm{C} / \mathrm{min}$, with no hold time for all samples other than the $1100^{\circ} \mathrm{C}, 24 \mathrm{~h}$ sample. Data from [67].

Figure 5 shows that the local structure of the geopolymer binder (bottom data set) is highly disordered beyond a length scale of approximately $10 \AA$, but shows significant structural ordering on a length scale below that [67]. Upon heating of the material beyond $1100^{\circ} \mathrm{C}$, the geopolymer crystallises to pollucite, which has a longer-range ordered structure, as seen by the distinct structural features at distances of up to $30 \AA$ in Figure 6. However, the local structure (below 8-10 $\AA$ ) remains largely unchanged during heating, indicating that the framework structure is very similar in the unheated geopolymer and in the crystalline pollucite, other than some minor differences which are able to be identified by partial PDF decomposition as being due to rearrangement of $\mathrm{Cs}^{+}$ions upon crystallisation [67]. Similar structural identifications through gel crystallisation have also been undertaken for potassium aluminosilicate geopolymers with $\mathrm{Si} / \mathrm{Al}=2$, which tend to resemble leucite $[68,69]$; the sodium-containing analogues at this $\mathrm{Si} / \mathrm{Al}$ ratio do not crystallise as readily to a single phase 
[70], which limits the use of this specific heating-based method for those materials. However, the identification of analcime-group phases in both the Cs- and K-containing systems did lead to the suggestion that the gel structure in a sodium aluminosilicate geopolymer may also share some structural features with analcime, and this assumption has been used successfully in the thermochemical description of the process of geopolymerisation in the presence of sodium $[38,39]$. Structural features characteristic of sodalite-group minerals, particularly 4-membered rings, have also been observed in the PDFs of $\mathrm{NaOH}$-activated metakaolin binders from very early age, long before crystalline phases are able to be observed crystallographically [47].

Pair distribution function analysis has also been applied in the area of construction materials science to the analysis of C-S-H structures $[65,71,72]$, and the analysis of the fundamental nature of metakaolin, a key supplementary cementitious material as well as an important geopolymer precursor [73-75]. This is a technique with enormous potential in enhancing the understanding of nanoscale-ordered phases, such as those which dominate the strength and durability performance of many construction materials, and is likely to gain in importance and accessibility as high- $Q$ capabilities are now becoming available on a wider range of laboratory diffractometers [76].

Another key structural characteristic of low-calcium geopolymeric materials is the fact that alkali cations are present in non-framework sites, compensating for the net negative framework charge induced by the substitution of tetrahedral $\mathrm{Al}$ for $\mathrm{Si}$. The cations will generally be associated with the oxygen atoms in the framework, rather than being located directly next to $\mathrm{Al}$ atoms (as is often drawn in structural sketches of geopolymer structures in the literature). There is a preference for larger alkali cations over smaller cations, with Cs noted to be preferentially bound (less leachable) compared to $\mathrm{Na}$ [77], and $\mathrm{K}$ known to be more rapidly and tightly included into the gel structure (preferentially partitioned from the pore solution into the solid state) than $\mathrm{Na}$ at early age $[78,79]$. Sodium cations are to some extent exchangeable, particularly in samples synthesised at high water/solids ratios [80], which raises questions around the possible leaching of alkalis from such materials, and potential consequences related to efflorescence. Efflorescence in geopolymers is often observed as the formation of alkali carbonate deposits on the surfaces of samples which have been held partially in contact with water [81-83], but can be controlled either through the provision of adequate sealed curing duration to enable the formation of a tortuous pore network, or by addition of Al-rich secondary binder components such as calcium aluminate cement or metakaolin [81]. 
While much of the discussion in the preceding few paragraphs has focused on metakaolinbased systems rather than those derived from fly ash, due largely to the greater amenability of metakaolin-based binders to analysis by advanced analytical techniques, many of the same structural concepts also hold true for fly ash-based geopolymers [24, 25, 84]. The work that has been conducted on these systems indicates a similar Q4-structured, pseudo-zeolitic gel as the reaction product of most low-calcium (Class $\mathrm{F}$ or siliceous) fly ashes undergoing geopolymerisation $[62,85,86]$, and so the structural similarities between these systems and the materials derived from metakaolin are often used to provide analogies between the systems. There are certainly important differences in gel chemistry between the two systems, particularly the fact that the fly ash-based binders can be produced at a much lower water/binder ratio than metakaolin-based systems due to the more amenable particle morphology of fly ash [87]. This couples with the Ca supplied by most fly ashes to give a more stable microstructure in these materials, which retain or gain strength with very longterm curing, compared to the often-observed partial crystallisation and gradual strength decrease of metakaolin-based geopolymers when kept in a warm and moist environment $[88,89]$.

\subsection{Higher-calcium alkali-activated binders}

Blast furnace slag is more reactive at moderately alkaline $\mathrm{pH}$ than fly ash or metakaolin, and so alkali-activation of slags can be achieved with a much broader range of activators, including alkali metal carbonate and sulfate solutions in addition to the hydroxides and silicates which are used in lower-calcium systems [1, 11, 90]. However, the majority of published work in these systems has related to higher-alkalinity activators, particularly silicates, as these provide more rapid setting and strength development under ambient curing conditions.

The products of the reaction between blast furnace slag and an alkali metal silicate or hydroxide solution are generally dominated by an aluminium-substituted calcium silicate hydrate gel [91]. This gel is tobermorite-like in structure, broadly comparable to the gel structure which results from Portland cement hydration (dominated by $\mathrm{Q}^{1}$ and $\mathrm{Q}^{2}$ silicon environments), but with a lower Ca content and more $\mathrm{Al}$ substitution into tetrahedral sites, particularly the bridging sites in the dreierketten type chains [33, 91]. This leads to a higher degree of polymerisation, and also a significant degree of crosslinking between tobermorite chains, evidenced by the presence of $\mathrm{Q}^{3}$ sites, and consistent with the Crosslinked Substituted Tobermorite Model developed recently for application to these binders [34]. However, once the $\mathrm{Al}$ content of the $\mathrm{C}-\mathrm{A}-\mathrm{S}-\mathrm{H}$ gel passes a certain limiting value 
(approximately one site in every 6-10 chain sites, depending on the chain length), the degree of crosslinking will start to decrease with further $\mathrm{Al}$ incorporation, as the formation of $\mathrm{Al}-\mathrm{O}$ Al bonds between tetrahedral sites is strongly disfavoured. So, crosslinking will not take place between chains which are saturated in $\mathrm{Al}$, and this leads to a decrease in both crosslinking extent and mean chain length [34].

There are also a wide range of secondary phases observed in alkali-activated binders derived from metallurgical slags, as shown schematically in Figure 6. This is a very approximate depiction of a chemically complex system, where the concentrations of at least 6 components (Ca, Mg, Si, Al, Na, S), as well as alkalinity, water/binder ratio and curing environment (duration, humidity and temperature), are all important in determining the exact phase assemblage formed.

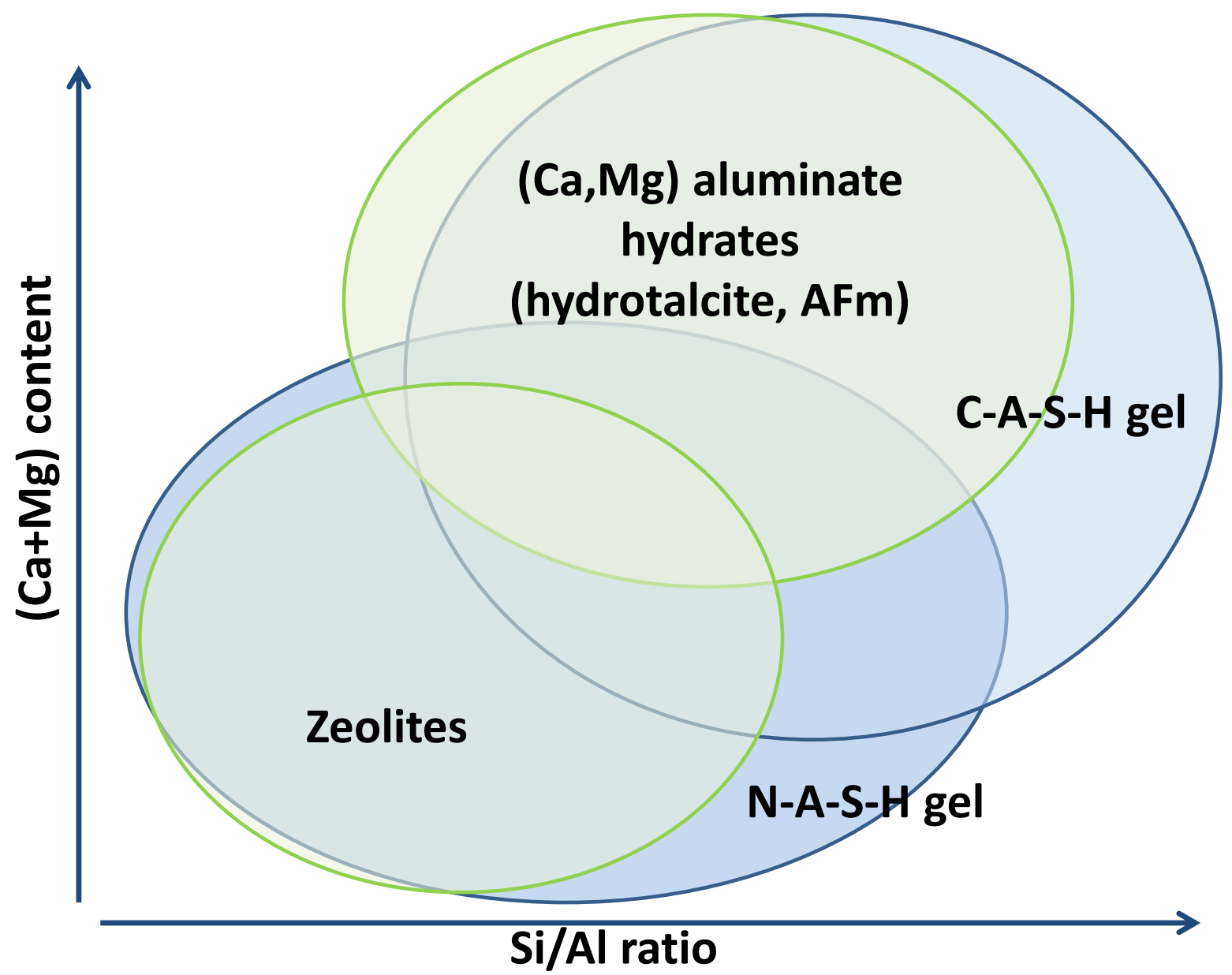

Figure 6. Schematic representation of phase formation within alkali-activated binders; ordered products are shown in green and disordered products in blue. Zeolites form as the main crystalline secondary products in systems with low Ca content and/or low Mg content, while hydrotalcite forms from Mg-rich slags, and AFm-type phases form in most blast furnace-slag based binders in the presence of sufficient Al. Data collated from many published studies including [1, 31, $34,44,62,92-96]$. 
Some key points to note from Figure 6 include:

- The C-A-S-H gel will include significant quantities of $\mathrm{Na}$, in defined charge-balancing sites and/or sorbed onto the gel itself, and so may also be written C-(N)-A-S-H. The role of the alkalis in the gel structure is beginning to be understood [97, 98], but the importance of the various secondary phases in determining the structural role of alkalis remains to be explored in detail.

- The degree of uptake of $\mathrm{Al}$ into the C-A-S-H gel is restricted by the chain structure of the tobermorite-like gel, and the thermodynamic preference for avoidance of Al-O-Al bonding within this gel phase [33, 34]. This means that the secondary phases will often be enriched in $\mathrm{Al}$ compared to the gel itself.

- Mg substitution into C-A-S-H type gels is limited, and so this element will react with $\mathrm{Al}$ to form hydrotalcite-type phases [34], often intimately intermixed with the silicate gel [91]. The use of slags with low Mg content will lead to the formation of zeolites instead of hydrotalcite [44].

- AFm type phases which form in alkali-activated binders at early age are often disordered and identifiable mainly by NMR; they become more distinct and crystalline at later ages [62].

- N-A-S-H type gels are very likely to coexist as a minor secondary product in addition to $\mathrm{C}-\mathrm{A}-\mathrm{S}-\mathrm{H}$ type gels within much of the compositional range of alkali-activated blast furnace slags [34], and in increasing prevalence in blends with fly ash [93] or metakaolin [22, 44].

The binder structure is more ordered when hydroxide activators are used, compared to silicate-activated binders which are much more amorphous in crystallographic terms [99]. The C-(N)-A-S-H gel in alkali silicate-activated slag systems is quite disordered, or at least ordered only on a length scale too short to measure by traditional crystallographic techniques. Both these and the more ordered $\mathrm{NaOH}$-activated slag systems have been analysed by the PDF technique [47, 48], and show significant evolution in local structure between early age ( 2 days) and more mature (128 days) binders. This is consistent with the

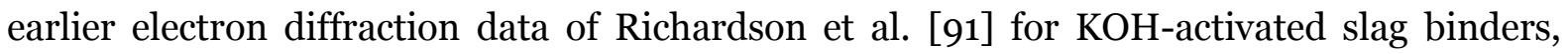
which are both relatively ordered (by the standards of cementitious gels) and have a sufficiently high $\mathrm{Al} / \mathrm{Si}$ ratio that the degree of crosslinking is low [91]. 
The chemical environments within alkali-activated binders are complex in terms of pore solution speciation and redox environments, and so much further work is required to fully validate the influence of pore solution chemistry on steel corrosion in particular. The ability of the highly alkaline pore solution to resist $\mathrm{pH}$ changes provides potentially interesting performance characteristics to these materials, although there are certainly complicating influences related to binder chemistry which remain to be fully unravelled [100]. This discussion thus leads to analysis of the characteristics of alkali-activated binders which enable (or in some cases hinder) the use of these binders to produce durable concretes, which is in the end the key aim of almost all cementitious binders used worldwide.

\section{Using alkali-activated binders to make durable concretes}

The key steps towards producing a useful alkali-activated concrete revolve around the design of an appropriate combination of binder, aggregates and admixtures which will give performance (rheology, strength and durability) which is fit for purpose in the desired application. In this context, it is important to consider various aspects of durability, including how it can be tested. This is discussed in detail in [1], but some brief comments follow:

- Carbonation of alkali-activated binders in service appears to be acceptably slow, in disagreement with the results of accelerated laboratory tests [100, 101]. This is related to the $\mathrm{pH}$ changes induced by different partial pressures of $\mathrm{CO}_{2}$ in alkaline solutions, and the consequent changes in gel structure [62, 101].

- Alkali-aggregate reactions in alkali-activated binders seem to be restricted by the high content of $\mathrm{Al}$ present, leading to the formation of non-expansive gels rather than damaging expansive products [102-105].

- Chloride penetration testing of alkali-activated materials has given results ranging from 'almost zero' to much higher than Portland cement concrete. This is largely a function of the fact that: (a) some standard testing methods are much more sensitive to pore solution chemistry than to actual chloride movement, leading to unreliable results when applied to non-Portland cements [1]; and (b) the pore structures of alkali-activated materials do actually span the range from highly impermeable to highly permeable, and this needs to be understood and better controlled [106].

- Sulfate resistance of alkali-activated concretes depends very much on the nature of the exposure environment; sodium sulfate, as commonly used in standard laboratory tests, has very little influence on most alkali-activated binders, while alkali-activated slag is subject to degradation by decalcification induced by the $\mathrm{Mg}$ in $\mathrm{MgSO}_{4}$ 
solutions [107]. However, whether this should really be considered 'sulfate attack' is another matter entirely, as it is really a process induced by $\mathrm{Mg}$.

These, and many other aspects of durability, are essential to the commercial-scale deployment of alkali-activated concretes. While acceptable field performance has been achieved by commercial alkali-activated concretes, and the scientific understanding of the phenomena which control these aspects of durability is rapidly increasing, it is essential to continue to build consensus regarding validation of testing methods for these materials. It is only in this way that the community will be able to build the technical confidence required for further standardisation of these materials in a wider range of jurisdictions and applications according to their technical potential.

\section{Concluding remarks}

This review has sketched links from fundamental alkali-activated binder chemistry to the use of these binders in producing construction materials. These binders are now attracting a great deal of attention for reasons of both technical and environmental performance, but their chemistry, reaction processes (including rheology), structure and durability must be better understood if the real capabilities of the materials are to live up to their advertised properties. Much progress has been made toward this end during the past decade, but further understanding is needed, particularly in multi-scale characterisation linking length scales on which transport processes and chemical reaction take place. This requires multidisciplinary insight spanning fields including, but not limited to: physics, chemistry (aqueous, solid-state and interfacial), materials science, chemical engineering, and civil engineering; each of these fields provides a different viewpoint from which the key questions can be addressed, bringing additional value by providing pathways around some of the subconscious assumptions which are specific to researchers in each other field. The chemical and physical processes involved in the synthesis and durability of concretes - either traditional or alkali-activated - take place across many orders of magnitude in both length and time scales, and thus provide complex questions requiring multi-faceted answers. This paper has been intended to sketch some answers while identifying further important questions related to the future of alkali-activation as a viable method of production of useful, durable concretes with reduced environmental impact compared to many of the materials currently in use. Much is now known about these materials, but much still remains to be known, and this provides both opportunities and challenges to researchers, practitioners, regulators and end-users. 


\section{Acknowledgements}

The work described here has been made possible through collaboration with many people over a number of years. A good share of the credit for the RILEM Robert L'Hermite Medal certainly belongs to the colleagues and students with whom I have worked over the past decade, and so I thank them for their input and hard work which has enabled me to write this review. First and foremost, I owe a major debt to Professor Jannie van Deventer, who has been my mentor, supervisor and longstanding collaborator (from both academic and industrial perspectives), and has given his unstinting support in every aspect of my career. My students and postdocs, I hope you have been able to learn from me some fraction of the amount I have learned from you, and I hope that my descriptions of your work have done justice to it. My collaborators and colleagues, in Melbourne, Sheffield, and all over the world (including RILEM TCs 224-AAM, 238-SCM, and 247-DTA), who have shared time, expertise, ideas and data with me, this has always been a pleasure. Among these people, particular thanks are due to Dr Peter Duxson, with whom discussions have always been thought-provoking, productive and fun, and have led (directly or indirectly) to much of the science described in this review. To those who have given me opportunities - and particularly the chance to take on a Chair at the University of Sheffield - I am truly grateful. To the agencies who have provided financial support, particularly the Australian Research Council through numerous projects, and also Zeobond as a key industry partner in much of my work, I hope that I have made good use of the money! Finally, and most importantly, to the person who proofreads and reality-checks all of my papers, my wife, collaborator, inspiration and partner in everything I do, Dr Susan A. Bernal - it's all for you.

\section{References}

1. Provis JL, van Deventer JSJ, eds. Alkali-Activated Materials: State-of-the-Art Report, RILEM TC 224-AAM. 2013, Springer/RILEM Publications: Berlin.

2. Duxson P, Provis JL (2008) Designing precursors for geopolymer cements. J Am Ceram Soc 91(12):3864-3869.

3. Provis JL. Activating solution chemistry for geopolymers. In: Provis JL, van Deventer JSJ, Geopolymers: Structure, Processing, Properties and Industrial Applications, Woodhead, Cambridge, UK. 2009, p. 50-71.

4. Davidovits J. Geopolymer Chemistry and Applications, Saint-Quentin, France: Institut Géopolymère, 2008.

5. $\quad$ Kühl H, Slag cement and process of making the same, U.S. Patent 900,939, 1908. 
6. Purdon AO (1940) The action of alkalis on blast-furnace slag. J Soc Chem Ind- Trans Commun 59:191-202.

7. Vanooteghem M. Duurzaamheid van beton met alkali-geactiveerde slak uit de jaren 50 - Het Purdocement. M.Ing. Thesis, Universiteit Gent, 2011.

8. Glukhovsky VD. Gruntosilikaty (Soil Silicates), Kiev: Gosstroyizdat, 1959.

9. Krivenko PV. Alkaline cements: From research to application. In: Lukey GC, ed. Geopolymers 2002 Turn Potential into Profit. Melbourne, Australia, Siloxo Pty. Ltd., 2002. CD-ROM Proceedings.

10. Husbands TB, Malone PG, Wakeley LD, Performance of Concretes Proportioned with Pyrament Blended Cement, U.S. Army Corps of Engineers Construction Productivity Advancement Research Program, Report CPAR-SL-94-2, Vicksburg, MS, 1994.

11. Shi C, Krivenko PV, Roy DM. Alkali-Activated Cements and Concretes, Abingdon, UK: Taylor \& Francis, 2006.

12. van Deventer JSJ, Provis JL, Duxson P (2012) Technical and commercial progress in the adoption of geopolymer cement. Miner Eng 29:89-104.

13. Habert G, Roussel N. A method for a fair allocation of the environmental impacts of supplementary cementitious materials. In: Palomo A, ed. XIII International Congress on the Chemistry of Cement. Madrid, Spain, 2011. CD-ROM.

14. von Weizsäcker E, Hargroves K, Smith MH, Desha C, Stasinopoulos P. Factor Five: Transforming the Global Economy Through 80\% Improvements in Resource Productivity, London, UK: Earthscan, 2009.

15. McGuire EM, Provis JL, Duxson P, Crawford R. Geopolymer concrete: Is there an alternative and viable technology in the concrete sector which reduces carbon emissions? In: Concrete 2011. Perth, Australia, Concrete Institute of Australia, 2011. CD-ROM proceedings.

16. McLellan BC, Williams RP, Lay J, van Riessen A, Corder GD (2011) Costs and carbon emissions for Geopolymer pastes in comparison to Ordinary Portland Cement. J Cleaner Prod 19(9-10):1080-1090.

17. Habert G, d'Espinose de Lacaillerie JB, Roussel N (2011) An environmental evaluation of geopolymer based concrete production: reviewing current research trends. J Cleaner Prod 19(11):1229-1238.

18. Duxson P, Provis JL, Lukey GC, van Deventer JSJ (2007) The role of inorganic polymer technology in the development of 'Green concrete'. Cem Concr Res 37(12):1590-1597.

19. Duxson P, Provis JL, Lukey GC, Separovic F, van Deventer JSJ (2005) ${ }^{29 S i ~ N M R ~}$ study of structural ordering in aluminosilicate geopolymer gels. Langmuir 21(7):3028-3036.

20. Shi C (2003) Corrosion resistance of alkali-activated slag cement. Adv Cem Res 15(2):77-81.

21. Shi C, Stegemann JA (2000) Acid corrosion resistance of different cementing materials. Cem Concr Res 30(5):803-808. 
22. Bernal SA, Rodríguez ED, Mejía de Gutierrez R, Gordillo M, Provis JL (2011) Mechanical and thermal characterisation of geopolymers based on silicate-activated metakaolin/slag blends. J Mater Sci 46(16):5477-5486.

23. Hooton $\mathrm{RD}$ (2008) Bridging the gap between research and standards. Cem Concr Res $38(2): 247-258$.

24. Duxson P, Fernández-Jiménez A, Provis JL, Lukey GC, Palomo A, van Deventer JSJ (2007) Geopolymer technology: The current state of the art. J Mater Sci 42(9):29172933.

25. Provis JL, van Deventer JSJ (2007) Geopolymerisation kinetics. 2. Reaction kinetic modelling. Chem Eng Sci 62(9):2318-2329.

26. Provis JL, van Deventer JSJ (2007) Geopolymerisation kinetics. 1. In situ energy dispersive X-ray diffractometry. Chem Eng Sci 62(9):2309-2317.

27. Provis JL, Walls PA, van Deventer JSJ (2008) Geopolymerisation kinetics. 3. Effects of Cs and Sr salts. Chem Eng Sci 63(18):4480-4489.

28. Faimon J (1996) Oscillatory silicon and aluminum aqueous concentrations during experimental aluminosilicate weathering. Geochim Cosmochim Acta 60(15):29012907.

29. Provis JL, Duxson P, Lukey GC, Separovic F, Kriven WM, van Deventer JSJ (2005) Modeling speciation in highly concentrated alkaline silicate solutions. Ind Eng Chem Res 44(23):8899-8908.

30. Knight CTG, Balec RJ, Kinrade SD (2007) The structure of silicate anions in aqueous alkaline solutions. Angew Chem Int Ed 46:8148-8152.

31. Lothenbach B, Gruskovnjak A (2007) Hydration of alkali-activated slag: Thermodynamic modelling. Adv Cem Res 19(2):81-92.

32. Chen W, Brouwers H (2007) The hydration of slag, part 1: reaction models for alkaliactivated slag. J Mater Sci 42(2):428-443.

33. Richardson IG (2004) Tobermorite/jennite- and tobermorite/calcium hydroxidebased models for the structure of C-S-H: applicability to hardened pastes of tricalcium silicate, $\beta$-dicalcium silicate, Portland cement, and blends of Portland cement with blast-furnace slag, metakaolin, or silica fume. Cem Concr Res 34(9):1733-1777.

34. Myers RJ, Bernal SA, San Nicolas R, Provis JL (2013) Generalized structural description of calcium-sodium aluminosilicate hydrate gels: The crosslinked substituted tobermorite model. Langmuir 29(17):5294-5306.

35. White CE, Provis JL, Kearley GJ, Riley DP, van Deventer JSJ (2011) Density functional modelling of silicate and aluminosilicate dimerisation solution chemistry. Dalton Trans 40(6):1348-1355.

36. White CE, Provis JL, Proffen T, van Deventer JSJ (2011) Quantitative mechanistic modeling of silica solubility and precipitation during the initial period of zeolite synthesis. J Phys Chem C 115(20):9879-9888. 
37. White CE, Provis JL, Proffen T, van Deventer JSJ (2012) Molecular mechanisms responsible for the structural changes occurring during geopolymerization: Multiscale simulation. AIChE J 58(7):2241-2253.

38. Zhang Z, Wang H, Provis JL, Bullen F, Reid A, Zhu Y (2012) Quantitative kinetic and structural analysis of geopolymers. Part 1 . The activation of metakaolin with sodium hydroxide. Thermochim Acta 539:23-33.

39. Zhang Z, Provis JL, Wang H, Bullen F, Reid A (2013) Quantitative kinetic and structural analysis of geopolymers. Part 2. Thermodynamics of sodium silicate activation of metakaolin. Thermochim Acta 565:163-171.

40. Alonso S, Palomo A (2001) Calorimetric study of alkaline activation of calcium hydroxide-metakaolin solid mixtures. Cem Concr Res 31(1):25-30.

41. Granizo ML, Blanco MT (1998) Alkaline activation of metakaolin - An isothermal conduction calorimetry study. J Therm Anal 52(3):957-965.

42. Puligilla S, Mondal P (2013) Role of slag in microstructural development and hardening of fly ash-slag geopolymer. Cem Concr Res 43:70-80.

43. Shi C, Day RL (1995) A calorimetric study of early hydration of alkali-slag cements. Cem Concr Res 25(6):1333-1346.

44. Bernal SA, Provis JL, Mejía de Gutierrez R, Rose V (2011) Evolution of binder structure in sodium silicate-activated slag-metakaolin blends. Cem Concr Compos 33(1):46-54.

45. Provis JL, Rees CA. Geopolymer synthesis kinetics. In: Provis JL, van Deventer JSJ, Geopolymers: Structure, Processing, Properties and Industrial Applications, Woodhead, Cambridge, UK. 2009, p. 118-136.

46. Provis JL, van Deventer JSJ (2007) Direct measurement of the kinetics of geopolymerisation by in-situ energy dispersive X-ray diffractometry. J Mater Sci 42(9):2974-2981.

47. White CE, Page K, Henson NJ, Provis JL (2013) In situ synchrotron X-ray pair distribution function analysis of the early stages of gel formation in metakaolin-based geopolymers. Appl Clay Sci 73:17-25.

48. White CE, Provis JL, Bloomer B, Henson NJ, Page K (2013) In situ X-ray pair distribution function analysis of geopolymer gel nanostructure formation kinetics. Phys Chem Chem Phys 15(22):8573-8582.

49. Steins P, Poulesquen A, Diat O, Frizon F (2012) Structural evolution during geopolymerization from an early age to consolidated material. Langmuir 28(22):8502-8510.

50. White CE, Provis JL, Llobet A, Proffen T, van Deventer JSJ (2011) Evolution of local structure in geopolymer gels: an in-situ neutron pair distribution function analysis. $J$ Am Ceram Soc 94(10):3532-3539.

51. Rees CA, Provis JL, Lukey GC, van Deventer JSJ (2007) In situ ATR-FTIR study of the early stages of fly ash geopolymer gel formation. Langmuir 23(17):9076-9082. 
52. Rees CA, Provis JL, Lukey GC, van Deventer JSJ (2008) The mechanism of geopolymer gel formation investigated through seeded nucleation. Colloids Surf A 318(1-3):97-105.

53. Hajimohammadi A, Provis JL, van Deventer JSJ (2011) Time-resolved and spatiallyresolved infrared spectroscopic observation of seeded nucleation controlling geopolymer gel formation. J Colloid Interf Sci 357(2):384-392.

54. Hajimohammadi A, Provis JL, van Deventer JSJ (2010) The effect of alumina release rate on the mechanism of geopolymer gel formation. Chem Mater 22(18):5199-5208.

55. Hajimohammadi A, Provis JL, van Deventer JSJ (2011) The effect of silica availability on the mechanism of geopolymerisation. Cem Concr Res 41(3):210-216.

56. Provis JL, Lukey GC, van Deventer JSJ (2005) Do geopolymers actually contain nanocrystalline zeolites? - A reexamination of existing results. Chem Mater 17(12):3075-3085.

57. Provis JL, Duxson P, Lukey GC, van Deventer JSJ (2005) Statistical thermodynamic model for Si/Al ordering in amorphous aluminosilicates. Chem Mater 17(11):29762986.

58. Loewenstein W (1954) The distribution of aluminum in the tetrahedra of silicates and aluminates. Am Miner 39(1-2):92-96.

59. Davidovits J (1991) Geopolymers - Inorganic polymeric new materials. J Therm Anal 37(8):1633-1656.

60. Rowles MR, Hanna JV, Pike KJ, Smith ME, O'Connor BH (2007) ${ }^{29} \mathrm{Si},{ }^{27} \mathrm{Al},{ }^{1} \mathrm{H}$ and ${ }^{23} \mathrm{Na}$ MAS NMR study of the bonding character in aluminosilicate inorganic polymers. Appl Magn Reson 32:663-689.

61. Barbosa VFF, MacKenzie KJD, Thaumaturgo C (2000) Synthesis and characterisation of materials based on inorganic polymers of alumina and silica: sodium polysialate polymers. Int J Inorg Mater 2(4):309-317.

62. Bernal SA, Provis JL, Walkley B, San Nicolas R, Gehman JD, Brice DG, Kilcullen A, Duxson P, van Deventer JSJ (2013) Gel nanostructure in alkali-activated binders based on slag and fly ash, and effects of accelerated carbonation. Cem Concr Res 53:127-144.

63. Ruiz-Santaquiteria C, Skibsted J, Fernández-Jiménez A, Palomo A (2012) Alkaline solution/binder ratio as a determining factor in the alkaline activation of aluminosilicates. Cem Concr Res 42(9):1242-1251.

64. Egami T (1990) Atomic correlations in non-periodic matter. Mater Trans JIM 31(3):163-176.

65. Meral C, Benmore CJ, Monteiro PJM (2011) The study of disorder and nanocrystallinity in C-S-H, supplementary cementitious materials and geopolymers using pair distribution function analysis. Cem Concr Res 41(7):696-710.

66. White CE (2012) Pair distribution function analysis of amorphous geopolymer precursors and binders: The importance of complementary molecular simulation. $\mathrm{Z}$ Kristallogr 227:304-312. 
67. Bell JL, Sarin P, Provis JL, Haggerty RP, Driemeyer PE, Chupas PJ, van Deventer JSJ, Kriven WM (2008) Atomic structure of a cesium aluminosilicate geopolymer: A pair distribution function study. Chem Mater 20(14):4768-4776.

68. White CE, Provis JL, Proffen T, van Deventer JSJ (2010) The effects of temperature on the local structure of metakaolin-based geopolymer binder: A neutron pair distribution function investigation. J Am Ceram Soc 93(10):3486-3492.

69. Bell JL, Sarin P, Driemeyer PE, Haggerty RP, Chupas PJ, Kriven WM (2008) X-ray pair distribution function analysis of a metakaolin-based, $\mathrm{KAlSi}_{2} \mathrm{O}_{6} \cdot 5 \cdot 5 \mathrm{H}_{2} \mathrm{O}$ inorganic polymer (geopolymer). J Mater Chem 18:5974-5981.

70. Duxson P, Lukey GC, van Deventer JSJ (2006) Evolution of gel structure during thermal processing of Na-geopolymer gels. Langmuir 22(21):8750-8757.

71. Skinner LB, Chae SR, Benmore CJ, Wenk HR, Monteiro PJM (2010) Nanostructure of calcium silicate hydrates in cements. Phys Rev Lett 104:195502.

72. Soyer-Uzun S, Chae SR, Benmore CJ, Wenk H-R, Monteiro PJM (2012) Compositional evolution of calcium silicate hydrate $(\mathrm{C}-\mathrm{S}-\mathrm{H})$ structures by total $\mathrm{X}$ ray scattering. J Am Ceram Soc 95(2):793-798.

73. White CE, Provis JL, Proffen T, Riley DP, van Deventer JSJ (2010) Combining density functional theory (DFT) and pair distribution function (PDF) analysis to solve the structure of metastable materials: the case of metakaolin. Phys Chem Chem Phys 12(13):3239-3245.

74. White CE, Provis JL, Proffen T, Riley DP, van Deventer JSJ (2010) Density functional modeling of the local structure of kaolinite subjected to thermal dehydroxylation. $J$ Phys Chem A 114(14):4988-4996.

75. White CE, Provis JL, Gordon LE, Riley DP, Proffen T, van Deventer JSJ (2011) The effect of temperature on the local structure of kaolinite intercalated with potassium acetate. J Am Ceram Soc 23(2):188-199.

76. Reiss CA, Kharchenko A, Gateshki M (2012) On the use of laboratory X-ray diffraction equipment for Pair Distribution Function (PDF) studies. Z Kristall 227(5):257-261.

77. Aly Z, Vance ER, Perera DS, Hanna JV, Griffith CS, Davis J, Durce D (2008) Aqueous leachability of metakaolin-based geopolymers with molar ratios of $\mathrm{Si} / \mathrm{Al}=1.5-4 . \mathrm{J}$ Nucl Mater 378(2):172-179.

78. Duxson P, Lukey GC, Separovic F, van Deventer JSJ (2005) The effect of alkali cations on aluminum incorporation in geopolymeric gels. Ind Eng Chem Res $44(4): 832-839$.

79. Duxson P, Provis JL, Lukey GC, van Deventer JSJ, Separovic F, Gan ZH (2006) ${ }^{39} \mathrm{~K}$ NMR of free potassium in geopolymers. Ind Eng Chem Res 45(26):9208-9210.

80. Bortnovsky O, Dědeček J, Tvarůžková Z, Sobalík Z, Šubrt J (2008) Metal ions as probes for characterization of geopolymer materials. J Am Ceram Soc 91(9):30523057.

81. Najafi Kani E, Allahverdi A, Provis JL (2012) Efflorescence control in geopolymer binders based on natural pozzolan. Cem Concr Compos 34(1):25-33. 
82. Škvára F, Kopecký L, Myšková L, Šmilauer V, Alberovská L, Vinšová L (2009) Aluminosilicate polymers - influence of elevated temperatures, efflorescence. CeramSilik 53(4):276-282.

83. Smith MA, Osborne GJ (1977) Slag/fly ash cements. World Cem Technol 1(6):223233 .

84. Provis JL, Harrex RM, Bernal SA, Duxson P, van Deventer JSJ (2012) Dilatometry of geopolymers as a means of selecting desirable fly ash sources. J Non-Cryst Solids 358(16):1930-1937.

85. Palomo A, Alonso S, Fernández-Jiménez A, Sobrados I, Sanz J (2004) Alkaline activation of fly ashes: NMR study of the reaction products. J Am Ceram Soc 87(6):1141-1145.

86. Shigemoto N, Sugiyama S, Hayashi H, Miyaura K (1995) Characterization of Na-X, $\mathrm{Na}-\mathrm{A}$, and coal fly ash zeolites and their amorphous precursors by IR, MAS NMR and XPS. J Mater Sci 30(22):5777-5783.

87. Provis JL, Duxson P, van Deventer JSJ (2010) The role of particle technology in developing sustainable construction materials. Adv Powder Technol 21(1):2-7.

88. Lloyd RR. Accelerated ageing of geopolymers. In: Provis JL, van Deventer JSJ, Geopolymers: Structure, Processing, Properties and Industrial Applications, Woodhead, Cambridge, UK. 2009, p. 139-166.

89. De Silva P, Sagoe-Crentsil K (2008) Medium-term phase stability of $\mathrm{Na}_{2} \mathrm{O}-\mathrm{Al}_{2} \mathrm{O}_{3}-$ $\mathrm{SiO}_{2}-\mathrm{H}_{2} \mathrm{O}$ geopolymer systems. Cem Concr Res 38(6):870-876.

90. Shi C, Day RL (1996) Selectivity of alkaline activators for the activation of slags. Cem Concr Aggr 18(1):8-14.

91. Richardson IG, Brough AR, Groves GW, Dobson CM (1994) The characterization of hardened alkali-activated blast-furnace slag pastes and the nature of the calcium silicate hydrate (C-S-H) paste. Cem Concr Res 24(5):813-829.

92. Ben Haha M, Le Saout G, Winnefeld F, Lothenbach B (2011) Influence of activator type on hydration kinetics, hydrate assemblage and microstructural development of alkali activated blast-furnace slags. Cem Concr Res 41(3):301-310.

93. Ismail I, Bernal SA, Provis JL, San Nicolas R, Hamdan S, van Deventer JSJ (2014) Modification of phase evolution in alkali-activated blast furnace slag by the incorporation of fly ash. Cem Concr Compos 45:125-135.

94. Wang SD, Scrivener KL (1995) Hydration products of alkali-activated slag cement. Cem Concr Res 25(3):561-571.

95. Krivenko PV. Alkaline cements. In: Krivenko PV, ed. Proceedings of the First International Conference on Alkaline Cements and Concretes. Kiev, Ukraine, VIPOL Stock Company, 1994. 11-129.

96. Gruskovnjak A, Lothenbach B, Holzer L, Figi R, Winnefeld F (2006) Hydration of alkali-activated slag: comparison with ordinary Portland cement. Adv Cem Res 18(3):119-128. 
97. Hong S-Y, Glasser FP (2002) Alkali sorption by C-S-H and C-A-S-H gels: Part II. Role of alumina. Cem Concr Res 32(7):1101-1111.

98. García-Lodeiro I, Palomo A, Fernández-Jiménez A, Macphee DE (2011) Compatibility studies between N-A-S-H and C-A-S-H gels. Study in the ternary diagram $\mathrm{Na}_{2} \mathrm{O}-\mathrm{CaO}-\mathrm{Al}_{2} \mathrm{O}_{3}-\mathrm{SiO}_{2}-\mathrm{H}_{2} \mathrm{O}$. Cem Concr Res 41(9):923-931.

99. Puertas F, Fernández-Jiménez A, Blanco-Varela MT (2004) Pore solution in alkaliactivated slag cement pastes. Relation to the composition and structure of calcium silicate hydrate. Cem Concr Res 34:139-148.

100. Bernal SA, San Nicolas R, Provis JL, Mejía de Gutiérrez R, van Deventer JSJ (2013) Natural carbonation of aged alkali-activated slag concretes. Mater Struct:in press, DOI 10.1617/s11527-11013-10089-11522.

101. Bernal SA, Provis JL, Brice DG, Kilcullen A, Duxson P, van Deventer JSJ (2012) Accelerated carbonation testing of alkali-activated binders significantly underestimates service life: The role of pore solution chemistry. Cem Concr Res 42(10):1317-1326.

102. Bakharev T, Sanjayan JG, Cheng YB (2001) Resistance of alkali-activated slag concrete to alkali-aggregate reaction. Cem Concr Res 31(2):331-334.

103. Fernández-Jiménez A, Puertas F (2002) The alkali-silica reaction in alkali-activated granulated slag mortars with reactive aggregate. Cem Concr Res 32(7):1019-1024.

104. Gifford PM, Gillott JE (1996) Alkali-silica reaction (ASR) and alkali-carbonate reaction (ACR) in activated blast furnace slag cement (ABFSC) concrete. Cem Concr Res 26(1):21-26.

105. Kupwade-Patil K, Allouche EN (2013) Impact of alkali silica reaction on fly ash-based geopolymer concrete. J Mater Civil Eng 25(1):131-139.

106. Lloyd RR, Provis JL, van Deventer JSJ (2010) Pore solution composition and alkali diffusion in inorganic polymer cement. Cem Concr Res 40(9):1386-1392.

107. Ismail I, Bernal SA, Provis JL, Hamdan S, van Deventer JSJ (2013) Microstructural changes in alkali activated fly ash/slag geopolymers with sulfate exposure. Mater Struct 46(3):361-373. 


\section{University Library}

\section{- M M N E R VA A gateway to Melbourne's research publications}

Minerva Access is the Institutional Repository of The University of Melbourne

Author/s:

Provis, JL

Title:

Geopolymers and other alkali activated materials: why, how, and what?

Date:

2014-01-01

Citation:

Provis, J. L. (2014). Geopolymers and other alkali activated materials: why, how, and what?. MATERIALS AND STRUCTURES, 47 (1-2), pp.11-25. https://doi.org/10.1617/ s11527-013-0211-5.

Persistent Link:

http://hdl.handle.net/11343/283014 